\title{
The Challenging Aspects of Digital Learning Objects Usage in a Primary School During the Pandemics
}

\author{
Raminta Jutaite ${ }^{1}$
}

\author{
Brigita Janiunaite ${ }^{2}$
}

\section{Jolita Horbacauskiene ${ }^{2}$}

\author{
${ }^{1} M A$, Kaunas University of Technology, \\ K. Donelaičio g. 73, Kaunas 44249, Lithuania \\ ${ }^{2}$ Professor, Kaunas University of Technology, \\ K. Donelaičio g. 73, Kaunas 44249, Lithuania
}

DOI: https://doi.org/10.36941/jesr-2021-0118

\section{Abstract}

The COVID-19 pandemic situation forced to look for other ways to provide continuous education around the world, which highlighted the importance and necessity of online education platforms and digital learning object (DLO) while going through this shift (Zhou et al., 2020; Viner et al., 2020; Wang et al., 2020). Teachers, in primary schools as well, had to reorganize completely their curriculum and assignments to adapt them to the virtual environment. This paper, based on the experiences of primary school teachers, aims to reveal the challenges faced by the teachers when within two weeks all Lithuanian schools and universities had to switch to remote education from face-to-face education and when the adoption of DLOs moved from optional to compulsory 'mode 'as learning process became remote. The research problem is analyzed primarily by revealing the theoretical aspects of the research, i.e., the concept of the DLO, the specifics of the adoption of DLOs in primary education and the challenges considered through the types of barriers. The findings indicate that teachers experienced challenges of practical training, issues in pupils' assessment due to the lack of participation in the process of assignment completion, time constrain, different computer systems used, issues of online security, internet access and support. The study also identified the challenges of practical origin, namely, difficulties in keeping pupils' concentration and attention throughout the lesson, lower level of teacher's control during lessons as well as differences in pupils' technical skills to use computers.

Keywords: digital learning object, primary school, teachers, challenges, barriers, Covid-19

\section{Introduction}

The integration of technology is becoming an increasing part of learning, therefore the educational process or a part of it is transferred to the digital environment. Digital learning objects (DLO) assist students in developing computer literacy and, therefore, prepare them for the technology influenced future. According to Vanderlinde, van Braak and Hermans (2009), one of the tasks of primary schools around the world is to integrate information and communication technologies into the teaching and 
learning process. Vanderlinde et al. (2014) argue that learning through the DLO is beneficial to primary school pupils because the school prepares the child for a future that is in any case connected with technologies. The DLO is designed to support learning, make teaching/learning content flexible and help ensure a successful learning process. DLOs promote primary school pupils 'motivation and engagement in lessons. The DLO is associated with increased pupil achievement, effective classroom work and development of different thinking skills in pupils. The benefits of adapting DLOs in education have been examined by a number of researchers (Singhavi and Basargekar, 2019; Scibeci et al., 2008; Nikolopoulos et al., 2012; Sherriff et al., 2019; Kurilovas, Kubilinskienė \& Dagienė, 2014; Janson \& Janson, 2009). Başaran (2016) and Marcus-Quinn and Mcgarr (2015) emphasise that to improve learning through DLOs, it is essential to combine multimedia (text, sound, graphics, animation, video recordings and simulations in the digital form) in a variety of ways (virtual learning environment, online storage, mobile devices). Singhavi and Basargekar (2019) argue that the quality of the DLO implementation depends on the teacher. By choosing to apply these objects in their lessons, teachers also accept new roles in their work, which changes the usual specifics of their work. Hubalovsky, Hubalovska and Musilek (2019), Loong and Herbert (2018), Kalaš et al. (2012), Taylor and Corrigan (2007), Zhu (2010) highlight the change of teacher's roles while implementing DLOs in primary education.

As in the implementation of innovation, in the application of the DLO teachers face a variety of challenges. Digital learning and DLO became even more relevant during the COVID-19 pandemic. The pandemic situation forced to look for other ways to provide continuous education around the world, which highlighted the importance and necessity of online education platforms while going through this shift (Zhou et al., 2020; Viner et al., 2020; Wang et al., 2020). Teachers, in primary schools as well, had to reorganize completely their curriculums and assignments to adapt them to the virtual environment. Taking into account the prior to crisis data from Teaching and Learning International Survey TALIS (see https://www.oecd.org/education/talis/ for more details ) conducted in 2018, the main findings concerning Lithuania's education system status quo highlighted the following aspects: only $62 \%$ of teachers let their students frequently or always use information and communication technologies (ICT) for classwork, while in Denmark and New Zealand the average was reported to be $80 \%$; the survey pointed out that not only younger teachers tend to use technologies more frequently but also those who had technology for teaching included into their formal training, meanwhile only $45 \%$ of teachers reported that the use of ICT was included into their formal education and/or training, while the average of OECD countries was $56 \%$. Lithuanian data indicate that $24 \%$ of teachers (compared to average of $18 \%$ of all participants) expressed a high need for ICT competence development, which emphasize the need to continuously renew their skills and adapt them to innovative technologies. The pandemic context forced all teachers despite their readiness to use DLO in remote teaching thus creating even bigger gaps in delivering quality instruction of remote teaching.

Although the TALIS survey revealed that $95 \%$ of students reported to have their own space for studying and $96 \%$ to have the computer for schoolwork, the EOCD report (2020) indicated the possible deterioration due to space and computer sharing with other family members during the lockdown.

This paper, based on the experiences of primary school teachers, aims to reveal the challenges faced by the teachers when within two weeks all Lithuanian schools and universities had to switch to remote education from face-to-face education and when the adoption of DLOs moved from optional to compulsory 'mode 'as learning process became distant.

The research problem is analyzed primarily by revealing the theoretical aspects of the research, i.e., the concept of the DLO, the specifics of the adoption of DLOs in primary education and the challenges considered through the types of barriers. The paper presents the methodology of the qualitative study and the results of the study, which are discussed in the context of tendencies of other research studies. Moreover, the study aims at revealing the DLO application challenges experienced by primary school teachers during Covid-19 pandemic period. 


\section{The Concept and Types of Digital Learning Objects}

Learning objects as a term originate from computer science where reusable objects are developed. Today, the profile of a learning object merges the principles of Computer and Educational Sciences. Moisey et al. (2006) suggest that the area is complex and complicated due to a number of existing terms seemingly referring to the same phenomenon, but different in their specificity and applicability. Moreover, the existent definitions and applications of learning objects are criticized. Due to their original roots being in Computer Science, they might be presented as directly unrelated to the learner and learning process. Nevertheless, according to Friesen (2004) the term learning object connects two words that are in many ways incompatible as learning express broad and general meaning while object conveys specificity and technological nature. Kay and Knaack (2008) follow the definition of learning objects as "interactive web-based tools that support the learning of specific concepts by enhancing, amplifying, and/or guiding the cognitive processes of learners" (p. 575), focusing more not on resources that have been developed specifically for educational purposes but on the learners 'cognitive processes. Pitkanen and Silander (2004) note that learning objects are linked to a whole learning process by the pedagogical interface and pedagogical functions they realize. Learning objects can be seen as digital „chunks of educational content” that can be implemented on any level of education (Sosteric \& Hesemeier, 2004). The typology suggested by Sosteric and Hesemeier (2004) of the existing definitions of learning objects specify four categories, namely [..."anything and everything (e.g. asset, component, and learning); anything digital either with/or without an educational goal (e.g. content object, information object, knowledge object, media object, raw media element, and reusable information object); anything for learning (e.g. educational object and learning object); digital learning objects for educational purposes in a specific learning environment (e.g. reusable learning object, unit of learning, and unit of study)...]" (p. 6-8). Allert (2004) proposes to categorize learning objects into first- and second-order learning objects, when first-order learning objects are developed or reused to reach a certain educational goal. Such learning objects are based on conveying information and include but are not limited to lectures, textbooks, and educational videos. Second-order learning objects are explained as those that contain diverse strategies and reflection, which in turn allows usage of active learning methods such as scaffolding, collaboration, etc., and fostering the development of a wide array of skills as decision-making, problem solving, planning, organizing, and self-directed learning. Shepherd (2006) highlights three types of learning objects, i.e., integrated, informal, and practiced and reviewed learning objects. Wiley (200o) argues that "any digital resource that can be reused to support learning" (p. 7) and can be used in multiple contexts represent best what the concept of learning object suggests in today's learning environment. Based on the presented definitions, it can be summarised that DLO is a digital or interactive entity or a resource that facilitates the educational process and has an educational purpose. The DLO can be used to facilitate, evaluate and verify the study process or create a course in the digital space.

\section{The Specificity of Adopting Digital Learning Objects in Primary Education}

Children enter the phase of specific operative thinking from the age of 7 . The thinking capabilities of children at this age start changing: they better understand the reasons, associate the received information with the already available experience and get closer to the adult model of thinking. However, it remains difficult for them to associate information with abstract ideas. Pupils associate and understand information through specific examples or depicted objects. For example, it is difficult for children to solve a simple arithmetical task expressed in words (Žukauskienè, 2012). Primary school children have a more developed visual rather than verbal memory. Children of this age tend to memorize things mechanically, which they achieve by simple repetition without understanding the meaningful connections of the memorized material (Kiseliova, Kiseliovas \& Salkuviené, 2013). Teachers have to understand the peculiarities of primary school learning and create an environment 
in the classroom that promotes thinking, independence, active exploration, individualization of tasks, ability to act by applying already-available knowledge/skills (Žukauskienè, 2012; Kubilinskienė \& Dagiene, 2010). Taking into account the characteristics of primary education, it is effective to apply digital learning objects to ensure the quality of learning (Kiseliova, Kiseliovas \& Salkuvienè, 2013). Vanderlinde et al. (2014) argue that learning through the DLO is beneficial to pupils of such age because the school prepares the child for the technology connected future. According to Goh, Bay and Chen (2015), it is important to monitor, coordinate and provide continuous support to children's learning through DLOs at an early stage of education. Thus, it can be argued that the role of the teacher in the classroom is changing to the teacher being a coordinator, a helper and the leader in the learning process. Hubalovsky, Hubalovska and Musilek (2019) emphasize that when starting to teach with DLOs, it is essential to make sure that learning is directed to children's motivation, age range and knowledge. The authors claim that e-learning tasks have to be colorful, interactive and supplemented with photos. Game elements should also be included and attention should be paid to the difficulty of the tasks. The internet is full of various and different information. This means that despite the positive aspects (e.g., finding the necessary information), incorrect or misleading information can also be encountered (Kalaš et al., 2012). Uibu and Kikas (2008) agree that the use of digital resources is associated with an oversupply of new material and information. Therefore, primary school teachers have to assess the authenticity and suitability of the material presented to pupils. According to Anastasiades and Vitalaki (2011), competent and professional teachers use information and communication technologies to promote internet security by teaching pupils ' appropriate behaviors when surfing the internet for educational, recreational, and interpersonal purposes. Primary school teachers need to be concerned about management of online sites and potential risks on the internet. In this way, they will be able to help pupils make meaningful use of the internet as a learning tool. Teachers, therefore, play an important role in protecting pupils and assessing the risks associated with the use of the internet and effective digital learning. Thus, teachers with more knowledge about the internet are more likely to integrate internet technologies into pupils' learning process. They are better at controlling and promoting internet security issues because they are better aware of the potential risks children may face online. With or without DLOs, the essential preparation for lessons and conducting classroom activities include planning, organization, conduct, evaluation, and feedback. The analysis of such activities helps to identify the challenges faced by primary school teachers in remote learning process.

\section{The Challenges of Applying Digital Learning Objects in the Context of Barrier Typology}

The word "challenge" may carry various connotations. In this paper, challenges will be evaluated through the prism of barriers, which allows to assess and interpret the obtained empirical results more accurately. Pirkkalainen and Pawlowski (2013) define a barrier as any challenge, risk, difficulty, restriction, or obstacle that may lead an individual, a group or an organization to failure, for example, in achieving the set goals. Sostrin (2009) defines a barrier as an obstacle, i.e., as any expressed behavior, attitude, assessment, or action that distracts, impedes, or prevents an individual, a team or an organization from learning or working. The emphasis is laid on the fact that educational and work environments encounter barriers everywhere and at all times. Barriers can either subtly affect daily communication and decision-making or have a systematic negative impact. Barriers, regardless of their nature and impact, undermine access to training and working. Ertmer et al. (1999) provide the classification of barriers that come up in the implementation of change and innovation. First order or external barriers, which are understood as challenges present in the implementation of new practices resulting from the environment in which the innovation is introduced. For example, barriers may arise from the lack of resources, time, effective teaching/learning or technical problems. Second order or internal barriers are related to people's perceptions or attitudes. They include resistance due to distrust, negative attitudes towards change, the lack of understanding of the benefits of innovation, unreliability of new instruments and their use and uncertainty in the application of innovation. 
Rogers (2000), Keengwe, Onchwari and Wachira (2008) identify external and internal barriers resulting from the application of technology in the educational process. They claim that the first order or external barriers relate to the lack of technology acceptance and accessibility, quality of support and insufficient skills of stakeholders (both learners and teachers). These barriers also relate to the lack of infrastructure, unreliable equipment, lack of technical support and resource-related issues (Keengwe et al., 2008; Bingimlas, 2009). The second order or internal barriers are related to the individual learner and include such factors as attitudes towards technology and user's level of competence (Rogers, 200o). These barriers include both school and teacher level factors. Factors at the school level are associated with organizational culture and its approach towards the adoption and application of technologies. Factors at the teacher level include personal beliefs in learning, technologies, and willingness to change (Keengwe et al., 2008; Bingimlas, 2009). Teachers' attitudes towards digital resources and their use in the educational process are formed through their previous experiences. The presented barrier classifications will serve as a basis for assessing the highlighted challenges in the empirical data.

\section{Methodology}

A semi-structured interview was employed to determine the challenges in the application of DLOs in primary education during the period of lockdown. This method allows to anticipate specific questions and come up with the sequence of their presentation in advance as well as the ability to ask additional questions during the course of the research contribute to a deeper understanding of the phenomena of the study. In a semi-structured interview, free formulation of questions allows for more flexibility in conducting interviews, since, depending on the answer, it is possible to clarify the question and various aspects of the phenomenon and analyze the phenomenon under study in a more thorough way (Kardelis, 2007; Galletta \& Cross, 2013). The advantage of the interviews as a means of communication is that the subjects naturally and spontaneously express their thoughts and emotions. On average, one interview lasted about 60 minutes.

The content analysis method was used to process the data collected during a semi-structured interview. To ensure the credibility of the interpretation of the data, peer debriefings were conducted to check preliminary findings and interpretations against the raw data (Nowell et al., 2017; Creswell \& Creswell, 2018). The results of the empirical study are illustrated by the respondents' original statements. The semi structured interview schemes specifically focused on the aspects of teachers' attitudes towards DLO in primary education, typology of DLO to clarify specific DLO examples used by primary school teachers, teacher's roles, and activities in applying DLO in different phases of the lesson (preparation, application, process evaluation / feedback), and possible barriers to DLO application.

In order to reveal the barriers to the application of the DLO in primary education, the convenience (non-probability) sample size method was chosen when the researchers themselves selected the respondents to be interviewed. A total of 8 primary school teachers working in private and public schools in two largest cities were interviewed. Before conducting a semi-structured interview, all teachers were introduced to the purpose of the study and ethical principles. During this study, the respondents gave their permission to record their interviews by a voice recorder. Due to the COVID-19 situation and the quarantine announced in Lithuania, the interviews were performed remotely, via Microsoft Teams and Zoom programs, which have chat recording functions. However, after assessing the possibility of (unintentional) leakage of information about the respondents to third parties, a safer option was chosen, namely a voice recorder. The respondents gave their permission to use the information provided by them only for the purposes of the study as long as their personal and other information were not disclosed. In semi-structured interviews, the respondents provided only the information they wanted to provide. 


\section{Results}

In order to clarify the teachers' attitudes towards DLO application in primary education, the respondents' answers were classified to positive and negative. The positive attitude was mentioned by most of the respondents. Teachers emphasize that it is interesting for a primary school pupil to learn in this way. Currently, children need to be prepared also for virtual life, learning with DLO develops the competencies a child may need in the future. Another important aspect mentioned by respondents is that technology is now an integral part of life and DLO is a daily routine for children. Finally, according to teachers, DLO expands learning opportunities by showing different ways of problem solving or learning about everyday processes. However, several teachers have been critical of DLO, arguing that it can bring both benefits and harms to children. The teacher needs to be competent and always consider whether and to what extent it will be useful in the lesson.

When answering the question "What digital learning resources do you use in your lessons?" primary school teachers identified that they use both digital platforms and games in their lessons. Since all teachers in the Covid-19 lockdown situation had to work remotely, Zoom, Microsoft Teams and the long-forgotten but newly revived Skype programs were used to conduct the lessons. Other Microsoft Office applications such as Power Point, Word, Forms were also used. Teachers created lessons and children prepared their presentations with Power Point. To measure children's knowledge, teachers created tests in the Microsoft Forms environment. Teachers also chose to use the YouTube environment to transmit video material; and the See Saw platform allowed the pupils not only to communicate information, but also to film themselves and place these videos on the platform. The respondents mentioned that they used electronic exercises and textbooks in their lessons, such as EDUKA, EMA and E. lankos. Various games were also used in lessons: 1) Kahoot, where children created or answered quiz questions themselves; 2) Plickers, used for instant checks of understanding, exit tickets or impromptu polls; 3) Scratch, where children created or played games that had been created beforehand; and 4) 1oMonkey where they could solve mathematical tasks. Several teachers mentioned that they used many different games that they had chosen by the topic and it would be difficult to list them all.

The semi structured interview data on teacher's roles and activities in applying DLO in different phases of the lesson (preparation, application, process evaluation / feedback) revealed the selection criteria for primary school teachers to select suitable DLO for the lesson, what criteria primary school teachers use to prepare the content of a lesson with DLO, and how in COVID-19 context teachers evaluate their work with DLO.

The analysis of the statements of the answers of the research participants revealed that the teachers value the experience of the colleagues, therefore the choice of DLO is based on their feedback and recommendations. An important selection criterion is the purpose of the lesson. Digital resources are selected based on what aim is planned to achieve in different lessons:

"Choose that platform or game to suit the purpose of the lesson" (interview 2); "to assess what we are going to do with that tool ... to reinforce knowledge, whether we want to introduce new things, or whether we want, well, some fun" (interview 7 ).

According to teachers, DLOs also have to be new ones that do not require high costs for the organization and are of high quality:

"When the DLO was updated, if the last update was in year 2015-2016, I may not necessarily use it" (4 interviews); "to be new" (interview 8).

Finally, the respondents consider and select the DLO according to the age of the children and their skills to use DLO, as well as time, cost and the evaluation given by pupils: 
"What is the age stage, what is relevant for these children" (interview 6); "the age of the children ... is it the first or the fourth grade, because the age of the children is different" (interview 7); "If most of the class is able to master certain tools, then I use it in the class" (interview 8).

"This is the opinion of pupils, their evaluation, which is important for me" (interview 5); "Then I appreciate the feedback from the students ... it is really that the children enjoy working with that platform" (interview 8).

Concerning the lesson content preparation using DLO, the respondents highlighted the pupils ' computer literacy skills so that they prepare their lessons in such a way that the content enables children not only to be listeners but also to be active participants:

"So that children are active participants in the lesson ... they can create their own content" (interview 5);

"I enable students to become $<. . .>$ content creators as well" (interview 8).

The following problematic aspects of teacher self-assessment in the application of DLO in their lessons were identified related to the current (remote learning) situation. The teachers have to spend more time to learn how to use new DLOs as all the teaching became remote. They also feel that they cannot control the lesson to full extend in some cases:

"I used to control the lesson, and now parents do it" (interview 5).

The quality of the lesson is assessed differently also due to the quality of teacher preparation and planning. However, according to teachers, preparation for the lesson directly correlated with lesson quality:

"If I prepare very well before the lesson, then the lesson is smoother. If I had less time and did not do so much planning, then that lesson may not be very successful" (interview 6); "I always do very well when I plan well <...>" (interview 7 ).

To identify the challenges of employing DLOs in primary education, the teachers were asked about the faced barriers when planning to use DLO. The analysis of the responses of the study participants showed that when planning to apply the DLO, teachers faced challenges with the diversification of tasks according to pupils' different technological literacy skills:

"I have problems with the diversification of the tasks" (interview 2); "I think that the main challenge $<. . .>$ is to diversify tasks" (interview 4); "how can we structure time when there is such a mixed picture in the classroom between those who know how to use the technologies and those who are not familiar with technologies quite enough" (interview 4); "one pupil obtains the information quickly and another pupil does it so much slower" (interview 5).

The lack of access to information and sources for teachers was also a challenge, as the school did not provide this possibility:

"In order to access certain platforms, we need to buy licenses <...: and our school does not give us such a possibility" (interview 8); "in normal environment, without pandemic, if we start remote learning process, we should have intensive training before the remote teaching (interview 6)".

Teachers also emphasized that the greatest challenge was the time. Teachers experienced the lack of time for preparing lessons, finding, and creating tasks. The time challenge also contributed to teachers worries that they would not cover the planned curriculum:

"We need time to prepare for the lessons but we do not have that much time <...>I make tests and slides myself, which takes up lots of time" (interview 3); "the curriculum itself is not allowing me to get deeper 
into technologies as I am afraid to not have time for going through the whole curriculum" (interview 5); "the lack of time brings about the most challenges" (interview 6); "the biggest challenge is <.. > the time" (interview 7); "Gust searching for information takes up a lot of time" (interview 8).

Another important challenge mentioned by the teachers was pupils 'concentration. Sometimes it was difficult for teachers to assess beforehand how pupils would react to one or another digital resource:

"The challenge is $<\ldots>$ children 's concentration $<\ldots . .>$ measuring how they will react" (interview 7 ).

At the organizational stage, teachers faced various challenges. Teachers, when organizing lessons with DLOs, had to prepare a number of lesson scenarios for any possible situation (technical issues, choice of DLO, etc.):

"I need to think about my options $<\ldots>$ what if the computer breaks down or the program that you created does not work" (interview 1); "you never know how that system will work $<\ldots>$ you need to think about option a, option b or even option c" (interview 4);"you need to have several options because you don't know if everything works or if there are any disturbances" (interview 5); "in Lithuania, everything is paid $<\ldots>$ it is the fact that everything costs money $<\ldots>$ the school does not invest in technologies, and we have to buy everything ourselves" (interview 2).

There were also challenges in ensuring online security, lack of equipment, time, technical challenges, planning and incompatibility of operating systems:

"The internet is not a safe space $<\ldots>$ when you watch YouTube $<\ldots>$ you never know what advertising is going to pop up" (interview 3); "you can't organize a lesson as you would like, because you realize that you don't have the necessary equipment" (interview 6); "technical things, whether everything will work, whether the internet connection will not be disturbed, whether all computers and tablets will work $\langle\ldots>$ you can plan the time, but you never know how much time it will take. So, it is difficult to measure the time needed" (interview 7); "the biggest challenge is that the equipment available to me and my pupils is different. I'm talking about operational systems" (interview 8).

When conducting lessons, teachers faced the lack of concentration of pupils' attention, as it was difficult for children to focus attention and keep it focused on one activity:

"It is difficult to keep pupils 'attention" (interview 1); "It is difficult to focus because there is so much information" (interview 3); "I feel that children are distracted and not everyone focus on what I show them (interview 6); "when pupils receive something very interesting or something very new, they want to share it with others" (interview 7); a "pupil gets tired very quickly during the lesson" (interview 3);" the child panics"(interview 4); "the child's anger is a serious challenge $<\ldots . .>$ because technologies take children out of balance" (interview 5).

Children willingly shared available information with other classmates and were distracted. There was also a noticeable lack not only of the pupils 'skills to use the computer, but also the lack of the resources themselves. For example, during the lessons, children worked with computers with different operational systems. Thus, children's reactions to the programs were different:

"Our little ones <...> can 't use the computers" (interview 2); "I have seventeen pupils in the classroom, but we do not have as many tablets $<\ldots>$ so I always have to divide pupils into groups. So individuality is gone" (interview 2). "Each child's computer works differently" (interview 4); "in the course of the lesson, sometimes the systems are lagging" (interview 1); "the internet connection can be cut off" (interview 6). 
Teachers also noted that when learning with the DLO, it was important to ensure pupils 'safety online:

"Ensuring online security” (interview 7).

However, sometimes the quality of the lesson could also depend on the internet connection itself:

"Each child's computer works differently" (interview 4); "in the course of the lesson, sometimes the systems are lagging" (interview 1); "technologies sometimes can trick you" (interview 5); the internet connection can cut you off" (interview 6); "the quality of the internet connection is of the highest importance" (interview 7).

The analysis revealed that teachers in the remote learning situation faced challenges in evaluating pupils during lessons with the DLO because they did not see the pupils 'work process:

"As a teacher you don't see the whole process. You see only the result" (interview 1); "if you are evaluating a test, which the child had done using Microsoft Forms, you can see the answers but you do not know whether the child had done it individually or with the help of the parents" (interview 2); "it is difficult to assess whether this is a the child 's contribution or the parent's contribution" (interview 3); "there are a lot of different activities and you do not have enough time to check everything and see whether your pupils have made any progress" (interview 6); "it is difficult to provide accurate assessment when you only see the final result <...> it is necessary to see the process of task solving" (interview 7).

Teachers encountered problems when evaluating the assignments as they were not able to monitor the process of the pupils' work. It was not known whether the pupils performed the tasks alone or with some help. It was also difficult to assess whether the pupil did not actually know the information or whether the result was influenced by a technical barrier. In addition, as it was mentioned before, pupils had unequal digital literacy skills.

'The biggest challenge is how to correctly and equitably evaluate $<\ldots . .>$ the level of digital literacy is very different in each child $<\ldots . .>$ you could call this the diversification of assessment" (interview 4); "children have different competencies $<\ldots . .>$ it is important to understand that content is different not because the pupil may not be able to do that task, but because he/she does not know how to manage the technology" (interview 8).

The analysis of the responses of the study showed that 7 out of 8 respondents mentioned the lack of time for a lesson because it was important to give individual feedback to each pupil:

'There is the lack of time for reflection <... If you can relate to their (children's) reflections $<\ldots . .>$ then you don't necessarily have time to give them feedback" (interview 1); "there is the lack of time for the feedback" (interview 3); "we need to provide feedback individually $<\ldots>$ there is the time challenge" (interview 4); "there is a problem with the time" (interview 5); "there is the lack of time for the lesson itself" (interview 6); "there is the lack of time because there are quite a few children in the classroom $<\ldots>$ choose the right way because the conversation <...> takes up a lot of time" interview 7); "the major challenge is the time" interview 8).

The respondents highlighted that feedback could be given when the teacher was able to evaluate the work process:

'You can't give feedback if you didn't see the work process" (interview 2). 
According to teachers, there were challenges in verifying the feedback when it was given in the digital format:

"How could we make and create such a simple system so that each child could send his/her work in as simple as possible manner and reduce the chances that they may make a mistake $<\ldots . .>$ and I am going to have to ask again and again "(interview 4); "how can we find out that the child has received the feedback. And then you have to double check. <...> that is to make sure that the feedback has indeed reached the pupils" (interview 7 ).

Teachers noted that they needed to check whether the children had received their feedback and ensure that the pupils read the feedback provided by the teacher.

The challenge for teachers was also ensuring that the pupils would not compare their achievements to each other:

"We are trying not to compare children with each other, which makes it very difficult $<\ldots . .>$ to not cause any negative emotions to pupils. Or very positive emotions, which would also lead to pupils being too arrogant" (interview 8).

This means that the feedback needs to be provided without an assessment and comparison among pupils.

Challenges also arose because not all children were able and sometimes not willing to acknowledge their work process:

"Not all pupils know how to self-evaluate themselves" (interview 6); "they can do the task, but they do not want to talk about it or about how it was for them to do it" (interview 8).

The results of the study also revealed that at the beginning of remote learning, parents were scared, confused, angry, in the unknown. It can be assumed that this feeling of their relationship with the teacher (in the short term) provided tension. After this period, the relationship with the parents is treated differently. One part of the respondents feels the support and willingness of parents to cooperate. Another is parental mistrust and assessment based only on pupils' well-being:

"In the beginning there was <...> anxiety, many questions, uncertainty like this" (interview 1); "in the beginning we were in the same boat, there were many angry letters <... panic and anger" (interview 3 ); "parents who are angry $<\ldots . .>$ really have a fear ... ... they do not deal with psychological things, they get stressed" (interview 5).

To sum up, the study confirmed the barriers or challenges identified in the scientific literature: barriers of time, practical training, equipment, lack of access, pupil assessment, online security, quality of the internet connection and support (first order or external); barriers of lack of knowledge, attitudes and beliefs and fear (second order or internal). The results also revealed additional barriers of practical origin: loss of teachers' control, incompatibility of operational systems, differentiation of tasks and evaluation, issues of mental health and concentration of attention of pupils, lack of computer skills of pupils, lack of visibility and insufficient work process of pupils.

\section{Discussion}

The results of the project carried out in $\mathbf{2 0 2 0}$ on remote education challenges and possibilities during pandemic period from the perspective of ecosystem identified that almost $46 \%$ of primary school pupils' parents and $36 \%$ of primary school teachers evaluated remote learning as more negative and negative, while only $14 \%$ of primary school teachers saw it as positive.

The study presented in the current paper showed that the onset of remote learning led to 
negative experiences for the teachers. The DLO had been used in the lessons before the pandemics for the diversification of the learning process. These results are consistent with Smeets' (2005) study in the sense that many primary school teachers use digital learning objects in their lessons as tools to supplement and diversify but not to replace the existing learning content. Primary school teachers experienced shock, suspense, and confusion due to the shift of the learning process to remote mode in the lockdown situation. The choice of appropriate learning tools to ensure successful learning, communication, co-operation, and evaluation was also questioned. Both at the beginning and at a later stage, there was a noticeable increase in teachers 'workload. In particular, teachers were required to reorganize assignments, activities, schedules and take the individual needs, skills of pupils into account. Carless (2013) highlights that teachers' negative attitudes towards technological innovation is associated with the additional workload.

To ensure quality learning, teachers were obliged to restore their emotional connection with the pupils. However, the study showed that the teacher-pupil relationship has changed, since it is difficult to feel the emotions and experiences of the pupil in the virtual environment. As a result, it could be argued that learning in the virtual space undermined the relationship between the pupil and the teacher. Changes also required active parental involvement. Primary school pupils are not yet proficient in self-learning, so they needed the help of not only teachers, but of their parents as well. It can be concluded that to achieve the goals of the lesson (at least at the beginning), teachers had to cooperate with the parents. At the beginning of remote learning, pupils' parents, similarly to the teachers, felt anxiety and fear of the new way of learning. The parents' anger and even panic were clearly felt in the process. The study showed that parents were not sure whether the new learning routine would ensure the quality and efficiency of the learning process. These insights are in line with the findings of study on remote education challenges and possibilities during pandemic period from the perspective of ecosystem (2020), where the parents' involvement (not only providing help to pupil but also cooperation with teachers) was found to be one of the main factors for primary school pupils' successful learning during pandemic period.

The results of the study showed that in today's situation, teachers are positive about their work and notice that their pupils 'independence has increased. However, a number of problematic aspects have also emerged. The loss of teacher 'control can be observed as the pupils are learning remotely. The evaluation of the quality of teachers' work also depends on the preparation of the plan. The emphasis is on the smooth and clear application of the DLO when the lesson is well planned and vice versa. The quality of the lesson suffers when the lesson is not properly planned (with the DLO). Thus, it can be concluded that to effectively apply the DLO in the lessons, teachers have to prepare a quality lesson plan. Finally, the problem areas are the lack of pupils 'skills and the lack of time to work with the computers. The problem of the lack of time is observed in the planning, organizational and feedback stages. Therefore, this is a complex problem. Teachers lack time: 1) choosing the DLO needed for the lesson; 2) anticipating technical challenges in the lessons; and 3) providing/receiving feedback in the lesson. Another challenge is the lack of computer skills that teachers experience when conducting a lesson. It usually results in teachers' lack of time to search and understand how to solve technical challenges and adapt DLOs in their lessons.

When planning lessons with DLOs, teachers face not only challenges arising from the lack of different skills and time, but also the diversification of tasks for the pupils. It can be assumed that the need for diversified tasks arises not only from different pupils 'knowledge but also from their unequal skills of computer literacy. The study showed other complex challenges of pupils 'concentration and access to the DLO. There are also challenges of pupils 'concentration during the course of the lessons as pupils find it difficult to maintain concentration and want to share their experiences out loud. Finally, in the planning and organizational stages, teachers face the lack of access to the DLO suitable for the lesson. Schools do not provide adequate licenses, and teachers themselves cannot buy them all. Rasmitadila et al. (2020) in their study highlight the necessity to ensure flexibility in curriculum, acceleration of technology readiness and teacher training for technology application.

The results of the study revealed that when organizing lessons with the DLO (in addition to the 
above-mentioned challenges of access and time), teachers faced online security issues because pupils are curious and aware that the internet can answer various questions that they have. These statements comply with the study results by Kalaš et. al. (2012), which claim that during the lessons, there are challenges of inappropriate or misleading information found on the Internet. When organizing lessons, teachers face barriers due to the lack of equipment, incompatibility of operational systems and the organization of different lesson scenarios. When organizing a lesson with DLOs, teachers have to consider other options if the choice of the DLO does not work or if the pupils' computers do not work. Thus, it can be assumed that one of the reasons why teachers have to come up with different lesson plans is the incompatibility of the teacher's and pupils' operational systems. This challenge is also encountered during the course of the lesson as the systems installed on pupils' computers are not the same. The lack of equipment and online security issues arise not only at the organizing stage but also at the planning stage. The results of the study confirm the findings of Voigt, Schön and Hofer (2018) that the lack of equipment for teachers is a barrier because it prevents pupils from working at their own pace. The study revealed that, in addition to the challenges mentioned above, teachers face the interferences in quality internet connection and pupils 'mental well-being. It has been noticed that pupils can quickly get angry, irritated and even cause panic in the lesson. Reflecting on the evaluation of the lessons with DLOs, teachers pointed out that it was particularly difficult to evaluate pupils in the remote learning process because the work process was not visible. There is a lack of accuracy in assessing the final product. Doubts arise whether pupils perform tasks independently or with the help of adults.

On the other hand, it is difficult for teachers to treat pupils equally as it is difficult to distinguish between the actual knowledge of the pupil and the inability to manage technology, especially if a pupil is not able to get the help from parents or siblings.

One more factor identified by respondents was feedback provision. It is important for teachers to see the individual progress of each pupil and compare it with other pupils, thus avoiding both negative and too positive emotions. As the interview data showed the respondents agree that they lacked the information on the pupils 'individual progress when completing the assignments due to various technical constrains. The study also revealed that not all primary school pupils are able to evaluate themselves and give feedback to teachers. In the case the feedback is provided using the DLO, then the challenges of ensuring the pupils read the feedback received from their teachers and the teachers receive feedback from the pupils could arise.

\section{Limitations and Suggestions for Future Research}

This study used a qualitative research design to explore the challenges of primary school teachers to use DLO in the context of COVID-19. This study was a small representation of primary school teachers who were forced to conduct the full teaching process on remote basis due to the unusual circumstances. For this reason, the future studies of similar origin to be more comprehensive require mixed method approach, addressing the challenges of using DLO from the perspective of parents as well as pupils. The research could be expanded to primary schools in various urban and rural regions.

\section{Concluding Remarks}

The study of the challenges of applying digital learning objects in the primary school in the context of COVID-19 revealed the following conclusions. Primary or external barriers include the following findings: teachers felt the lack of time for choosing the right DLOs for their lessons and ensuring feedback in the lessons. The lack of visibility of the pupils 'learning process created challenges for teachers in assessing pupils 'assignments and their knowledge. Teachers singled out the lack of practical training, which would help to acquire new knowledge and skills. The study also highlighted other resource-related barriers: the lack of equipment and access, online security and internet connection. For these reasons, teachers also face challenges in the organization and application of the 
DLO in lessons. The study also revealed some external barriers that are not highlighted in the presented literature review: 1) teachers felt the loss of control in the lesson as the pupils worked from home; 2) incompatibility of operating systems, as teachers and pupils work with different computer systems, and in the case of challenges, teachers cannot always help; 3 ) it is difficult for teachers to evaluate and diversify tasks for the pupils due to the already mentioned invisibility of the learning process; 4) it is difficult to ensure the mental health and concentration of pupils, as pupils are quickly distracted, angry or even panicked; 5) pupils 'lack of computer skills hinders teachers from achieving the lesson goals because at the same time teachers have to address technical challenges; 6) insufficient planning, as the quality of the lesson with the DLO depends on the plan prepared by the teacher. The results of the study indicate that the secondary or internal barriers arise from the lack of knowledge about DLOs, teachers' attitudes and beliefs, possible fear of DLO. The study also revealed other internal barriers not discussed in the scientific literature: teachers experienced emotional shock, anxiety and doubt due to the reorganization of the teaching/learning process caused by the COVID-19 pandemics. The results show that more effective use of DLO in classrooms requires teachers to have the right equipment and access to quality programs as well as targeted training. Teachers would also like to receive support and parental cooperation in developing students' computer literacy skills. Based on the results of the study, the possibilities for reducing barriers are related to resources or/ and their access, barriers to lack of time, lack of support, increasing students' mental health and concentration, developing students' computer skills, ensuring online security, diversification of assignments and evaluation.

\section{References}

Allert, H. (2004). Coherent social systems for learning: An approach for contextualized and community-centred metadata. Journal of Interactive Media in Education, 2004(1), 7. https://doi.org/10.5334/2004-2-allert

Anastasiades, P. S., \& Vitalaki, E. (2011). Promoting Internet Safety in Greek Primary Schools: the Teacher's Role. Educational Technology \& Society, 14(2), 71-80.

Başaran, S. (2016). Multi-criteria decision analysis approaches for selecting and evaluating digital learning objects. Procedia Computer Science, 102, 251-258. https://doi.org/10.1016/j.procs.2016.09.398

Bingimlas, K. A. (2009). Barriers to the successful integration of ICT in teaching and learning environments: A review of the literature. Eurasia journal of mathematics, science \& technology education, 5(3), 235-245.

Carless, D. (2013). Innovation in Language Teaching and Learning. C. A. Chapelle (Ed.) The Encyclopedia of Applied Linguistics, Blackwell Publishing Ltd. DOI:10.1002/9781405198431.wbealo540. p.1-4.

Creswell, J. W., \& Creswell, J. D. (2018). Research design: Qualitative, quantitative, and mixed methods approaches. Sage publications.

Ertmer, P. A., Paul, A., Molly, L., Eva, R., \& Denise, W. (1999). Examining teachers' beliefs about the role of technology in the elementary classroom. Journal of Research on Computing in Education, 32(1), 54-72. https://doi.org/10.1080/o8886504.1999.10782269

Friesen, N. (2004). The international learning object metadata survey. The International Review of Research in Open and Distributed Learning, 5(3). https://doi.org/10.19173/irrodl.v5i3.195

Galletta, A., \& Cross, W. E. (2013). Mastering the semi-structured interview and beyond: From research design to analysis and publication. NYU Press.

Goh, W. L. W., Bay, S., \& Chen, V. H. (2015). Young school children's use of digital devices and parental rules. Telematics and Informatics, 32(4), 787-795. https://doi.org/10.1016/j.tele.2015.04.002

Hubalovsky, S., Hubalovska, M., \& Musilek, M. (2019). Assessment of the influence of adaptive E-learning on learning effectiveness of primary school pupils. Computers in Human Behavior, 92, 691-705. https://doi.org/10.1016/j.chb.2018.05.033

Janson, A., \& Janson, R. (2009). Integrating Digital Learning Objects in the Classroom: A Need for Educational Leadership. Innovate: Journal of Online Education, 5(3), 4.

Kalaš, I., Bannayan, H. E., Conery, L., Laval, E., Laurillard, D., Ping Lim, Ch., Musgrave, S., Semenov, \& A., Turcsányi-Szabó, M. (2012). ICT in Primary Education: Analytical survey. UNESCO Institute for Information Technologies in Education. https://iite.unesco.org/pics/publications/en/files/3214707.pdf

Kardelis, K. (2007). Mokslinių tyrimų metodologija ir metodai. Šiauliai: Lucilijus. 
Kay, R. \& Knaack, L. (2008). An examination of the impact of learning objects in secondary school. Journal of Computer Assisted Learning, 24, 447-461. doi:10.1111/j.1365-2729.2008.00278.x.

Keengwe, J., Onchwari, G., \& Wachira, P. (2008). Computer technology integration and student learning: Barriers and promise. Journal of Science Education and Technology, 17(6), 56o-565. https://doi.org/10.1007/s10956oo8-9123-5

Kiseliova, D., Kiseliovas, A., \& Šalkuvienė, O. (2013). Aritmetinių vaizdinių formavimas IV-V klasėse taikant virtualiuosius mokymo (si) objektus. Žvirblių takas, (3), 24-31.

Kubilinskienè, S., \& Dagienė, V. (2010). Technology-Based Lesson Plans: Preparation and Description. Informatics in Education, 9(2), 217-228.

Kurilovas, E., Kubilinskiene, S., \& Dagiene, V. (2014). Web 3.0 - Based personalisation of learning objects in virtual learning environments. Computers in Human Behavior, 30, $654-662$. https://doi.org/10.1016/j.chb.2013.07.039

Loong, E. Y., \& Herbert, S. (2018). Primary school teachers' use of digital technology in mathematics: The complexities. Mathematics Education Research Journal, 3o(4), 475-498. https://doi.org/10.1007/s13394-018o235-9

Nowell, L. S., Norris, J. M., White, D. E., \& Moules, N. J. (2017). Thematic Analysis: Striving to Meet the Trustworthiness Criteria. International Journal of Qualitative Methods, (16), 1-13. https://doi.org/10.1177/1609406917733847

Marcus-Quinn, A., \& Mcgarr, O. (2015). Teachers 'Use of Reusable Learning Objects in Teaching English Poetry: Exploring the Influence of Prevailing Pedagogical Practices. Education XXI, 18(1), 325-344.

Moisey, S. D., Ally, M., \& Spencer, B. (2006). Factors affecting the development and use of learning objects. American Journal of Distance Education, 20(3), 143-161. https://doi.org/10.1207/s15389286ajde2003_3

Nikolopoulos, G., Solomou, G., Pierrakeas, C., \& Kameas, A. (2012). Modeling the characteristics of a learning object for use within E-learning applications. Proceedings of the Fifth Balkan Conference in Informatics on BCI '12. 112-117, https://doi.org/10.1145/2371316.2371338

Pirkkalainen, H., \& Pawlowski, J. (2013). Global social knowledge management: from barriers to the selection of social tools. Electronic Journal of Knowledge Management, 11(1), 3-17.

Pitkanen, S. H., \& Silander, P. (2004). Criteria for pedagogical reusability of learning objects enabling adaptation and individualised learning processes, IEEE International Conference on Advanced Learning Technologies, Proceedings, Joensuu, 2004, 246-250, doi: 10.1109/ICALT.2004.1357412.

Rasmitadila, R., Aliyyah, R. R., Rachmadtullah, R., Samsudin, A., Syaodih, E., Nurtanto, M., \& Tambunan, A. R. (2020). The perception of Primary School teachers of online Learning during the COVID-19 Pandemic Period: A Case Study in Indonesia. Journal of Ethnic and Cultural Studies, Vol.7 (2), 90-109. https://doi.org/10.29333/ejecs/388

Rogers, P. L. (2000). Barriers to adopting emerging technologies in education. Journal of Educational Computing Research, 22(4), 455-472. https://doi.org/10.219o/4uje-b6vw-azon-mce5

Shepherd, C. (2006). Objects of Interest. [electronic resource] ULR: http://www.fastrakconsulting.co.uk/tactix/features/objects/objects.htm.

Sherriff, G., Benson, D., \& Atwood, G. (2019). Practices, Policies, and Problems in the Management of Learning Data: A Survey of Libraries' Use of Digital Learning Objects and the Data They Create. The Journal of Academic Librarianship, 45(2), 102-109. https://doi.org/10.1016/j.acalib.2018.12.005

Singhavi, C., \& Basargekar, P. (2019). Barriers Perceived by Teachers for Use of Information and Communication Technology (ICT) in the Classroom in Maharashtra, India. International Journal of Education and Development Using Information and Communication Technology, 15(2), 62-78.

Smeets, E. (2005). Does ICT contribute to powerful learning environments in primary education? Computers \& Education, 44(3), 343-355. https://doi.org/10.1016/j.compedu.2004.04.003

Sosteric, M. \& Hesemeier, S. (2002). When is a learning object not an object: a first step towards a theory of learning objects. International Review of Research in Open and Distance Learning 3 (2), 1-16. https://doi.org/10.19173/irrodl.v3i2.106

Sostrin, J. (2009). A conceptual framework of barriers to workplace learning and performance. OD Practitioner, $41(3), 42-49$.

Taylor, N., \& Corrigan, G. (2007). New South Wales Primary School Teachers' Perceptions of the Role of ICT in the Primary Science Curriculum - A Rural and Regional Perspective. International Journal of Science and Mathematics Education,5(1), 85-109.

Uibu, K., \& Kikas, E. (2008). The Roles of a Primary School Teacher in the Information Society. Scandinavian Journal of Educational Research, 52(5), 459-48o. https://doi.org/10.108o/o0313830802346348 
Vanderlinde, R., Aesaert, K., \& Van Braak, J. (2014). Institutionalised ICT use in primary education: A multilevel analysis. Computers \& Education, 72, 1-10. https://doi.org/10.1016/j.compedu.2013.10.007

Vanderlinde, R., van Braak, J., \& Hermans, R. (2009). Educational technology on a turning point: curriculum implementation in Flanders and challenges for schools. Educational Technology Research and Development, 57(4), 573-584. https://doi.org/10.1007/s11423-009-9126-9

Viner, R. M., Russell, S. J., Croker, H., Packer, J., Ward, J., Stansfield, C., \& Booy, R. (2020). School closure and management practices during coronavirus outbreaks including COVID-19: a rapid systematic review. The Lancet Child \& Adolescent Health.

Voigt, C., Schön, S., \& Hofer, M. (2018). Innovation management in schools: Barriers and enablers to making as educative practice. Multikonferenz Wirtschaftsinformatik (MKWI), March 06-09, 2018, Lüneburg, Germany, 833-844.

Wang, G., Zhang, Y., Zhao, J., Zhang, J., \& Jiang, F. (2020). Mitigate the effects of home confinement on children during the COVID-19 outbreak. The Lancet, 395(10228), 945-947. https://doi.org/10.1016/so140$6736(20) 30547^{-x}$

VU mokslininkų projektas „Nuotolinis vaikų ugdymas pandemijos dèl Covid-19 metu: grèsmès bei galimybės ekosisteminiu požiūriu“ finansuojamas (sut.nr.S-COV-20-11). https://www.fsf.vu.lt/dokumentai/Dokumentainuorodos/VU_mokslinink\%C5\%B3_projekto_rekomendacijos.pdf

Wiley, D. A. (200o) "Connecting Learning Objects to Instructional Design Theory: A Definition, a Metaphor, and a Taxonomy." In D. A. Wiley (ed.), The Instructional Use of Learning Objects. [Electronic resource] URL: http://reusability.org/read/chapters/wiley.doc.

Zhou, L., Li, F., Wu, S., \& Zhou M. (2020) "School's Out, But Class's On", The largest online education in the world today: Taking China's practical exploration during the COVID-19 epidemic prevention and control as an example. Best Evid Chin Edu, 4(2):501-519. Doi: 10.15354/bece.20.aro23.

Zhu, C. (2010). Teacher roles and adoption of educational technology in the Chinese context. Journal for Educational Research Online, 2(2), 72-86.

Žukauskienė, R. (2012). Raidos psichologija: integruotas požiūris. Vilnius: Margi raštai. 